\title{
Hard to reach: easy to omit
}

See linked article by Stirland et al.

on pg 282

\section{*Mark RD Johnson ${ }^{a}$}

a Professor of Diversity in Health \& Social Care, Mary Seacole Research Centre, De Montfort University \& Centre for Evidence in Ethnicity Health and Diversity, University of Warwick, UK

*Correspondence:

Professor Mark RD Johnson

Mary Seacole Research Centre, CEEHD

De Montfort University,

Hawthorne Building, The Gateway

Leicester

LE1 9BH

UK

Tel: +44 (0)1676 532389

E-mail: mrdj@dmu.ac.uk

Commissioned article Not externally peer-reviewed Accepted 15th April 2011

Online 8th July 2011
It is now some time since Mahvash Hussain-Gambles' and Mason and colleagues 'blew the whistle' on the exclusion of minority ethnic groups from clinical research trials, but that scandal seems to continue. Sheikh and colleagues have done us a service by adding to the literature - and indeed, their previous contributions ${ }^{3}$ - by exploring in a paper published in this issue of the Primary Care Respiratory Journal the practical suggestions made by a group of UK- and US-based researchers working with minority ethnic informants largely around issues associated with asthma. ${ }^{4}$

Asthma is, of course, a condition that has often been associated with a reaction to exposure to increased levels of pollutants following migration, ${ }^{5}$ although some other studies point to a protective effect in younger migrants - showing lower levels of asthma in the years immediately following migration. ${ }^{6}$ It is easy to see why researchers find research with this group a fruitful source of insights into the causation of disease, and why 'ethnicity' creates a useful research tool for epidemiologists and aetiologists. However, it is also clear that - as in other areas of health research - the investment in 'science' has paid few dividends for members of minority communities.?

Not surprisingly, Stirland et al. ${ }^{4}$ highlight the need for trust-building to overcome barriers or suspicions which may impede inclusion of minority groups in research. ${ }^{8}$ The infamous 'Tuskegee' experiment in the United States ${ }^{9}$ - which led fairly directly to the creation of the President's Council on bioethics, and perhaps indirectly to the National Institutes of Health (NIH) 'Revitalisation Act' of 1993 - while not widely known among European populations of minority or migrant origin, has its parallels here too. The creation of respect and working relationships between marginalised minority communities and researchers takes time and effort (and indeed, resources) but in the long run will be to everyone's benefit. One might, for example, point out that according to the 2011 Census of India, about 1 in 6 of the world's population (1.2 billion) are Indian; and if we extend this to the other major nations of the sub-continental region and their diasporas, it is likely that the South Asian total approaches a quarter of the global population - not merely the $0.7 \%$ of the American population or 4\% (in 2011) of the UK population that are apparent to many 'western' researchers. With increasing globalisation, and with the commercial imperative to ensure that medications can be safely prescribed and sold across the world, inclusive research seems an obvious necessity.

In fact, one wonders why it took legislation and executive action to make the change in America. The policy of the NIH (based on that Revitalisation Act) is quite clear:

"... women and members of minority groups and their subpopulations must be included in all $\mathrm{NIH}$-supported biomedical and behavioral research projects involving human subjects, unless a clear and compelling rationale and justification establishes ... that inclusion is inappropriate with respect to the health of the subjects or the purpose of the research. ${ }^{10 "}$

Similarly, and recently updated, the American National Heart, Lung, and Blood Institute states on its website that

"When designing and developing a phase III trial, the investigator must evaluate all relevant data to assess whether or not the trial should include adequate numbers of subgroups of participants to allow for separate and adequately powered analyses. Even if no such evidence is available, the trial must include sufficient numbers of women and minorities to conduct valid analyses (that is, unbiased assessment) of subgroup effects. ${ }^{11 "}$ 
Clearly, as Stirland et al. indicate, ${ }^{4}$ there are logistical implications arising from such an inclusive strategy; there will be additional costs involved at least in preparing information in more than one language, and time will be needed to set up and check more complex monitoring and sampling frames. ${ }^{12}$ What is more, recruitment and consenting techniques may need to be adapted for less commonly-accessed populations, and more attention given to the transferability and usefulness of certain concepts or routinelyused survey questions and 'standardised' instruments. ${ }^{13-15}$ However, as the NIH sites state very clearly, "Cost is not an acceptable reason for exclusion except when the study would duplicate data from other sources". Furthermore, collaborative and inclusive research is more likely to lead to effective and acceptable interventions, which will in due course reduce the costs and needs for health care through better outcomes in marginalised groups who (in general) currently have worse health and possibly also may incur higher costs in treatment. ${ }^{16}$

It will also be desirable to make those marginalised and hitherto 'hard to reach' groups aware of the findings of the research in which they are involved. The only way to ensure continued participation by these hitherto excluded groups is to give explicit attention to feeding back scientific results and consequent service-related outcomes to those communities so that they can see the value of participation to their social groups and community networks. However, the benefits should outweigh the costs, and we look forward to future research, such as that of Lakhanpaul and co-workers, ${ }^{17}$ which takes the approach even further. In the new model - taking the notion of user engagement to its logical next step and with the urging of local community members - they are seeking to develop interventions in the management of asthma which will meet the specific needs of their local South Asian (minority ethnic) populations, with potentially enormous implications for the future. And these implications will apply to other conditions, not just respiratory diseases...

\section{Conflicts of interest}

None

\section{References}

1. Hussain-Gambles M, Leese B, Atkin K, Brown J, Mason S, Tovey P. Involving South Asian patients in clinical trials. Health Technol Assess 2004;8:42.

2. Mason S, Hussain-Gambles M, Leese B, Atkin K, Brown J. Representation of South Asian people in randomised clinical trials: analysis of trials' data. BMJ 2003;326:1244-5. http://dx.doi.org/10.1136/bmj.326.7401.1244

3. Sheikh A, Halani L, Bhopal R, et al. Facilitating the recruitment of minority ethnic people into research: qualitative case study of South Asians and asthma. PLoS Med 2009; 6: e1000148. http://dx.doi.org/ 10.1371/journal.pmed.1000148

4. Stirland L, Halani L, Bhopal R, et al. Recruitment of South Asians into asthma research: qualitative study of UK and US researchers. Prim Care Respir J 2011; 20:282-90. http://dx.doi.org/10.4104/pcrj.2011.00032

5. Rottem M, Szyper-Kravitz M, Shoenfeld Y. Atopy and asthma in migrants. Int Arch Allergy Immunol 2005;136(2):198-204. http://dx.doi.org/10.1159/000083894

6. Bhopal R. Is research into ethnicity and health racist, unsound, or important science? BMJ 1997;314:1751-6.

7. Whitrow MJ, Harding S. Asthma in Black African, Black Caribbean and South Asian adolescents in the MRC DASH study: a cross sectional analysis. BMC Pediatr 2010;10:18. http://dx.doi.org/10.1186/1471-2431-10-18

8. Wendler $D$, Kington $\mathrm{R}$, Madans J, et al. Are racial and ethnic minorities less willing to participate in health research? PLOS Med 2006;3:e19. http://dx.doi.org/10.1371/journal.pmed.0030019

9. Centers for Disease Controls 2009: "U.S. Public Health Service Syphilis Study at Tuskegee" (accessed 6 April 2011) http://www.cdc.gov/tuskegee/timeline.htm

10. NIH Guidelines on the Inclusion of Women and Minorities as Subjects in Clinical Research (2000) http://grants.nih.gov/grants/guide/notice-files/not-od-00048.html accessed 6 April 2011

11. National Heart, Lung, and Blood Institute National Institutes of Health 2011 Questions and Answers on Inclusion of Minorities and Women in Study Populations http://www.nhlbi.nih.gov/funding/policies/nhlbigui.htm

12. Johnson MRD, Szczepura A. 2003 Representation of South Asian people in randomised trials: Population's ethnic profile should be recorded in all medical data. BMJ (letters);327:394). http://dx.doi.org/110.1136/bmj.327.7411.394-b

13. Johnson MRD, Borde T. Representation of ethnic minorities in research Necessity, opportunity and adverse effects. In Marginalized Reproduction: Ethnicity, Infertility and Reproductive Technologies (Eds Lorraine Culley, Nicky Hudson and Floor van Rooij). London: Earthscan. 2009 Chapter $4: 64-80$ (ISBN: 978-1-84407-576-8)

14. CE Lloyd, J Sturt, MRD Johnson, S Mughal, G Collins, AH Barnett. Development of alternative methods of data collection in South Asians with Type 2 diabetes. Diabetic Medicine (advance publication: http://dx.doi.org/10.1111/j.14645491.2008.02401.x (website - http://www.blackwell-synergy.com/doi/abs/ 10.1111/j.1464-5491.2008.02401.x )

15. Lloyd CE, Johnson MRD, Mughal S, et al. Securing recruitment and obtaining informed consent in minority ethnic groups in the UK. BMC Health Services Research 2008;8:68. http://www.biomedcentral.com/1472-6963/8/68. doi:10.1186/1472-6963-8-68

16. Johnson MRD, McGee P. Is diversity equality a local concern or an international marker of quality for public health? (Editorial). Diversity in Health \& Care 2010; 7(4):225-8.

17. Lakhanpaul M, Culley LA, Bird D et al. The use of a collaborative structured methodology for the development of a multifaceted intervention programme for the management of asthma, tailored to the needs of children and families of South Asian origin" (protocol for an NIHR Health services research study). 2010. http://www.hsr.nihr.ac.uk/projects/09_2001_19.asp

\section{Available online at http://www.thepcrj.org}

